Revista Eletrônica do Mestrado em Educação Ambiental

\title{
PROGRAMA DE EDUCAÇÃO AMBIENTAL: O EMPREGO DE INDICADORES DE SUSTENTABILIDADE
}

\author{
Fabricio Baron Mussi ${ }^{1}$ \\ Loise Cristina Schwarzbach ${ }^{2}$ \\ Alboni Marisa Dudeque Pianovski Vieira ${ }^{3}$
}

Resumo: A presente pesquisa tem como objetivo analisar um projeto desenvolvido pela Usina Hidrelétrica de Itaipu para promoção de encontros/oficinas de educação ambiental com os pescadores profissionais que atuam ao longo do reservatório, a partir de uma perspectiva de análise que concilie indicadores de resultado de natureza quantitativa e qualitativa. A análise teve como apoio teórico os estudos de Mikhailova (2004), Elkington (2001), Bohringer; Jochem (2007), Boulanger (2008), Bell e Morse (2011), entre outros. Foi empregado o método de estudo de caso. A triangulação de entrevistas, documentos internos e a observação das oficinas de educação ambiental indicaram que os resultados mais relevantes do programa são de natureza qualitativa. Sugere-se, por fim, a avaliação longitudinal do programa, a fim de acompanhar a evolução dos indicadores identificados.

Palavras-chave: Educação Ambiental; Usina de Itaipu; Indicadores de Sustentabilidade.

\section{PROGRAMA DE EDUCACIÓN AMBIENTAL: EL EMPLEO DE INDICADORES DE SOSTENIBILIDAD}

Resumen: La presente investigación tiene como objetivo analizar un proyecto desarrollado por Usina Hidroeléctrica de Itaipú para la promoción de encuentros y talleres de educación ambiental con los pescadores profesionales que actúan a lo largo del embalse, a partir de una perspectiva de análisis que compagine indicadores de resultado de naturaleza cuantitativa y cualitativa. El análisis tuvo como apoyo teórico los estudios de Mikhailova (2004), Elkington (2001), Bohringer; Jochem (2007), Boulanger (2008), Bell y Morse (2011), entre otros. Se utilizó el método de estudio de caso. La triangulación de entrevistas, documentos internos y la observación de los talleres de

\footnotetext{
${ }^{1}$ Mestre em Administração pela UFPR. Professor da Faculdade União das Américas, em Foz do Iguaçu, PR. Doutorando em Administração. Gestor de Contratos no Departamento de Reservatório e Áreas Protegidas da Itaipu Binacional. Contato: fabricio_mussi@hotmail.com

${ }^{2}$ Doutoranda e Mestre em Administração pela UFPR. Doutoranda em Administração pela PUCPR. Bolsista Capes. Contato: loisecs@live.com

${ }^{3}$ Mestre e doutora em Educação. Professora do Programa de Pós-Graduação em Educação (M/D) da Pontifícia Universidade Católica do Paraná - PUCPR. Contato: alboni@ alboni.com
}

Rev. Eletrônica Mestr. Educ. Ambient. Rio Grande, v. 36, n. 2, p. 126 -147, mai./ago. 2019. 
educación ambiental indicaron que los resultados más relevantes del programa son de naturaleza cualitativa.

Palabras-clave: Educación ambiental; Usina Hidroeléctrica de Itaipú; Indicadores de sostenibilidad.

\title{
ENVIRONMENTAL EDUCATION PROGRAM: THE EMPLOYMENT OF SUSTAINABILITY INDICATORS
}

\begin{abstract}
The objective of this research is to analyze, combining quantitative results and qualitative indicators, a project developed by the Itaipu Hydroelectric Power Plant, which promotes environmental education meetings/workshops with professional fishermen who work along the reservoir. The analysis was supported by Mikhailova (2004), Elkington (2001), Bohringer; Jochem (2007), Boulanger (2008), Bell and Morse (2011), among others. The case study method was used. The triangulation of interviews, internal documents and the observation of environmental education workshops indicated that the most relevant results of the program are of a qualitative nature. Lastly, it is suggested that the program be longitudinally evaluated in order to monitor the evolution of the indicators identified.
\end{abstract}

Keywords: Environmental Education; Itaipu Hydroelectric Power Plant; Sustainability indicators

\section{Introdução}

A sustentabilidade tem sido debatida sob múltiplas perspectivas (ELKINGTON, 2001; BOFF, 2002), as quais envolvem questões majoritariamente relacionadas ao desenvolvimento social, econômico e ambiental. O tema aborda, entre outras possibilidades, a necessidade de revisar a utilização de recursos, visando o bem-estar das gerações futuras (MIKHAILOVA, 2004). Destacam-se as iniciativas governamentais voltadas à promoção da sustentabilidade e, em especial, aquelas promovidas por grandes empresas com o intuito de envolver as comunidades que a circundam ou que foram afetadas por grandes empreendimentos. Nesse contexto, as ações voltadas à educação ambiental podem auxiliar no fomento às mudanças por meio da participação dos atores sociais que interferem no ambiente, incitando as comunidades a assumirem uma postura proativa na busca por soluções a partir da compreensão da realidade a sua volta como instrumento de aprendizado (VITORASSI, 2014).

Essas iniciativas, por sua vez, devem ser examinadas a partir de indicadores que assegurem a possibilidade de avaliação dos resultados. A esse respeito, parte da literatura sugere a adoção de indicadores definidos por experts, a fim de cumprir o rigor científico e metodológico que o tema requer, o que implica na possibilidade de generalização e ampla utilização desses indicadores (BOHRINGER; JOCHEM, 2007; BOULANGER, 2008; MOLDAN; JANOUSKOWÁ; HAK, 2012). Outra parte, porém, defende maior 
flexibilidade na criação de indicadores, buscando aproximá-los da realidade estudada, ainda que disso decorra certa perda de rigor. Recomenda-se, aqui, a utilização de indicadores de natureza qualitativa, de forma a complementar aqueles quantitativos (BELL; MORSE, 2001).

No setor elétrico brasileiro, a usina Hidrelétrica de Itaipu desenvolve um amplo programa de Educação Ambiental voltado à sensibilização e à formação dos diversos atores e grupos sociais para atuarem na construção de sociedades sustentáveis, e ainda visando formar, sensibilizar e envolver diversos segmentos da sociedade em processos reflexivos, críticos e emancipatórios (ITAIPU, 2010). Uma das frentes de atuação desse programa refere-se à educação ambiental levada à área de influência da usina, compreendendo os seguintes públicos: professores, alunos, agricultores, pecuaristas, trabalhadores rurais, pescadores, assentados, índios, catadores de material reciclável, donas de casa, lideranças comunitárias, comerciantes, representantes de instituições parceiras, merendeiras, nutricionistas e representantes de todas as prefeituras municipais.

Uma iniciativa de avaliação global desse programa foi empreendida por Vitorassi (2014), contudo, a avaliação específica para esses públicos ainda representa um terreno fértil para pesquisa, visto que poucas publicações empreendem esforços na avaliação de programas de educação ambiental. Para Vitorassi, essas despendem esforços nas dificuldades da avaliação, mas pouco na proposição de estratégias que considerem as especificidades dos programas de educação ambiental.

Diante do exposto, esse trabalho tem como propósito analisar um projeto desenvolvido pela Usina Hidrelétrica de Itaipu para promoção de encontros/oficinas de educação ambiental com os pescadores profissionais que atuam ao longo do reservatório, a partir de uma perspectiva de análise que conciliasse indicadores de resultado de natureza quantitativa e qualitativa. Espera-se, a partir desse exame, aprimorar as possibilidades de contribuição para a educação ambiental dessa classe e, concomitantemente, refinar os instrumentos de avaliação de iniciativas dessa natureza.

O estudo inicia-se com o levantamento teórico, a partir da perspectiva da sustentabilidade e seus indicadores, bem como a educação ambiental. Em seguida, são descritos os procedimentos metodológicos. Posteriormente, apresenta-se a caracterização do projeto e sua análise e, por fim, são descritas as conclusões e recomendações para pesquisas futuras.

\section{Referencial teórico}

Rev. Eletrônica Mestr. Educ. Ambient. Rio Grande, v. 36, n. 2, p. 126 -147, mai./ago. 2019. E-ISSN 1517-1256 


\subsection{Sustentabilidade corporativa}

Um dos desafios políticos e gerenciais não só da atual geração, mas também dos últimos 150 anos, tem sido o pensar no desenvolvimento econômico e bem-estar social sem que um prejudique o outro (DYLLICK; HOCKERTS, 2002). O uso inadequado dos recursos naturais tem sido recorrentemente debatido, a exemplo do livro de Rachel Carson, de 1962, $1^{\text {a }}$ edição, intitulado Primavera silenciosa, o qual levantou um movimento ambientalista sobre o uso de pesticidas, além de discutir a poluição do meio ambiente no seu aspecto mais social. Outros eventos que também abordaram, cronologicamente, o tema meio ambiente foram o World Commission on Environment and Development (WCED), em 1987, e o Rio Earth Summit 1992, nos quais a principal discussão consistiu em conciliar o desenvolvimento do bem-estar social, o crescimento econômico e o uso adequado dos recursos naturais (KEATING, 1993).

Uma das referências na questão da sustentabilidade refere-se ao relatório Our Common Future, de 1987, fruto do WCED, quando o desenvolvimento sustentável foi definido como "[...] o desenvolvimento que atende às necessidades do presente sem comprometer a capacidade das gerações futuras de satisfazer as suas próprias necessidades"4 (WCED, 1987, p. 41).

As discussões sobre o tema levaram à criação da Agenda 21, promovida também pelo Rio Earth Summit 1992 (UNESCO, 1992), que se propunha a reverter a pobreza mundial e promover a preservação do meio ambiente. Esse documento serve também como um guia às organizações, às empresas e aos indivíduos para orientar nas escolhas menos degradantes ao meio ambiente e operacionalizar o conhecimento rumo a um estilo de vida sustentável. Ao transpor a discussão de sustentabilidade para o nível dos negócios, a sustentabilidade corporativa pode ser definida como:

Satisfazer as necessidades das partes interessadas direta e indiretamente de uma empresa (tais como acionistas, empregados, clientes, grupos de interesse, comunidades, etc.), como também não comprometer sua capacidade de atender às necessidades de futuras das partes interessadas (DYLLICK; HOCKERTS, 2002, p. 132).

A sustentabilidade (responsabilidade ambiental), enquanto conceito, está relacionada ao ritmo de consumo que pode continuar indefinidamente sem degradar os estoques totais de capital (MIKHAILOVA, 2004). O conceito de sustentabilidade pode ser

\footnotetext{
${ }^{4}$ No original: "Sustainable development is development that meets the needs of the present without compromising the ability of future generations to meet their own needs" (WCED, 1987, p. 41).
}

Rev. Eletrônica Mestr. Educ. Ambient. Rio Grande, v. 36, n. 2, p. 126 -147, mai./ago. 2019. 
visto de uma perspectiva transdisciplinar. No contexto da geração de energia, as questões relacionadas à sustentabilidade abarcam, em especial, os seguintes temas: impactos ambientais; impactos socioeconômicos; benefícios socioeconômicos (BRASIL, 2014). Outro ponto a ser discutido, nesse contexto, refere-se à seguinte indagação: o que envolve a sustentabilidade? A esse respeito, Elkington (2001) apresenta a teoria dos três pilares (Triple Bottom Line), afirmando que, para ser sustentável, a empresa deve promover iniciativas que impactem nas dimensões sociais, ambientais e econômicas. A figura a seguir ilustra os três pilares a que esse autor se refere:

Figura I - Os três pilares da sustentabilidade

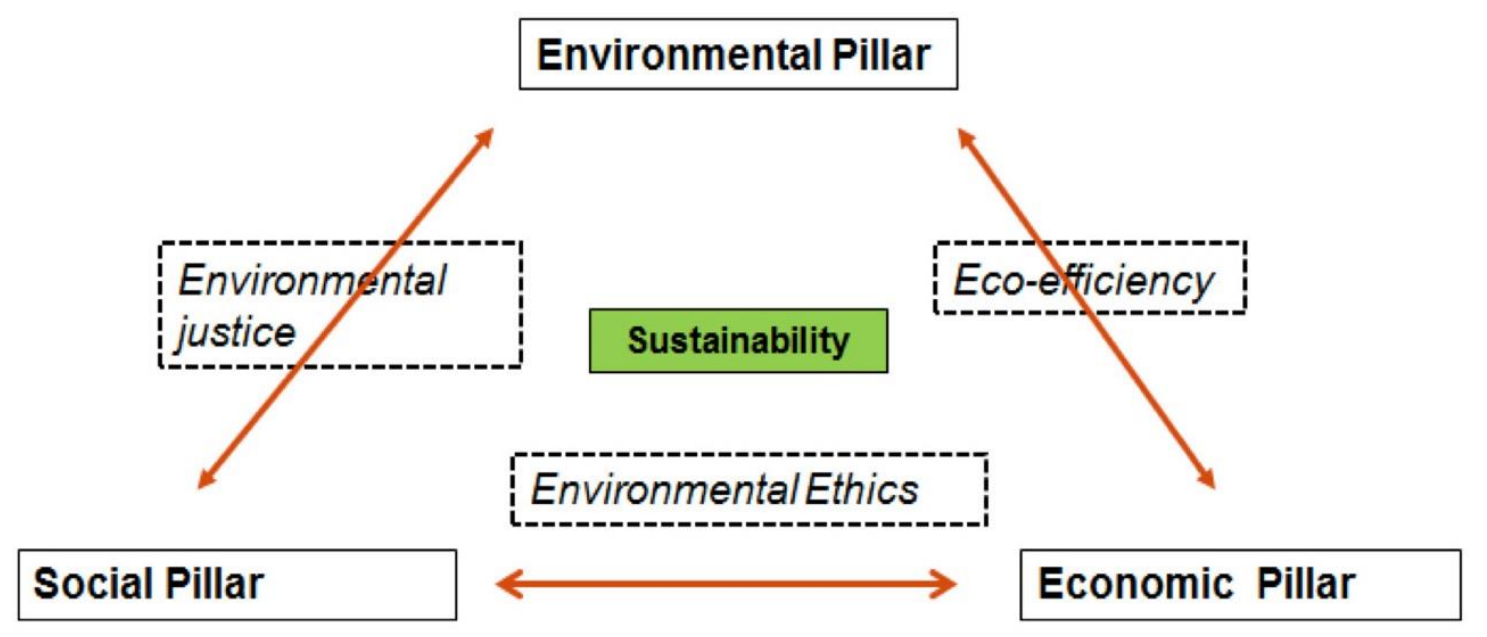

Fonte: Elkington (2001)

A teoria Triple Bottom Line representa um tema sobre o qual o campo de estudo da sustentabilidade foi desenvolvido e ganhou expressão. O objetivo do modelo é procurar o equilíbrio entre a eficiência econômica, a equidade social e a preservação do meio ambiente (ELKINGTON, 2001). Deve-se observar que esses campos se diferenciam quanto as suas prioridades no âmbito regional de aplicação do conceito, pois, por exemplo, na Europa Ocidental, a preocupação maior está na sustentabilidade ambiental, enquanto que na África, a dimensão social é mais respeitada (SILVIUS; SCHIPPER, 2010).

O conceito de sustentabilidade corporativa significa adotar práticas organizacionais tendo como base os princípios do Triple Bottom Line. Dentre os objetivos da adoção dessa abordagem pelas organizações, pode-se citar a geração de ganhos para proteção ao meio ambiente, a criação de uma demanda maior rumo a um mercado ecologicamente produtivo e servir de modelo de influência para organizações, outras empresas e famílias (INTERNATIONAL..., 2000), ou ainda, motivados pela propagação da reputação e acesso 
a novos conhecimentos (ORSATO et al., 2015). Contudo, alguns autores (CAVALCANTE et al., 2007; REZENDE et al., 2007; MACHADO et al., 2009) afirmam que não há evidências concretas de que a participação de empresas nessas frentes promove retornos financeiros.

Segundo Barbieri (2008), as empresas estão entre as principais forças condutoras da sociedade, influenciando tanto em nível global quanto em relação ao interior dos lares, seja por decisões multilaterais ou de rotina. Apenas produzir e vender dentro da lei não satisfaz, sem que haja um esforço pela união da gestão ambiental à responsabilidade social corporativa. Ao aderir ao movimento social que clama por sustentabilidade, há necessidade de se substituir as formas e práticas antigas para traduzir os princípios, as diretrizes e os objetivos do novo movimento social (BARBIERI et al., 2010).

\subsection{Indicadores para a sustentabilidade}

Tendo exposto o que o conceito de sustentabilidade abrange, outro ponto a ser esclarecido refere-se às possibilidades de mensurá-lo, sendo que a forma usualmente empregada para isso consiste no uso de indicadores (BOHRINGER; JOCHEM, 2007; BOULANGER, 2008; MOLDAN; JANOUSKOWÁ; HAK, 2012). Assim como em outras áreas do conhecimento (como as ciências econômicas e as ciências exatas, por exemplo), a utilização de indicadores serve como parâmetro de mensuração e avaliação, uma referência necessária para que a empresa avalie o quão eficiente são (ou têm sido) suas iniciativas voltadas à sustentabilidade.

\subsubsection{Indicadores quantitativos}

Bohringer e Jochem (2007) discutem a crescente utilização de indicadores como referência para formulação de políticas públicas e para avaliação das mudanças nas áreas econômica, social e ambiental. Os autores observaram a necessidade de se atender aos critérios científicos de normalização (tornar as variáveis compráveis), a agregação (compilar indicadores em fórmulas específicas) e a ponderação (atribuição de pesos diferentes, conforme a relevância do indicador). Com relação aos índices já utilizados para se avaliar a sustentabilidade, a agregação e a atribuição de pesos são realizadas de modo arbitrário e subjetivo, sendo que a agregação não se utiliza de métodos que lhe confiram consistência e significância. 
A esse respeito, a definição de indicadores deveria obedecer ao rigor estatístico que o método científico exige. Wagenhals et al. (2014) argumentam sobre a necessidade de se visualizar a interdependência entre os indicadores que são utilizados para se avaliar a sustentabilidade, apontando o quanto a ausência dessa preocupação leva a conclusões incompletas na análise dos índices.

Assim, na avaliação quantitativa, os resultados advindos de uma análise criteriosa sobre a estrutura do programa, seus processos e resultados almejados são passíveis de mensuração numérica (MINAYO, 2005).

\subsubsection{Indicadores qualitativos}

Em contraposição aos autores supracitados, Bell e Morse (2011) alertam para a ideia de os indicadores serem utilizados de forma reducionista, a fim de apropriar-se de apenas parte de um contexto: o emprego do indicador, interpretado como fornecendo a visão do todo foi, entretanto, conseguido por intermédio de uma análise apenas parcial. Aqui, acrescenta-se que o reducionismo é de natureza essencialmente metodológica, com vistas a se impor o mesmo procedimento científico - em nome do rigor do método independentemente das idiossincrasias do contexto, algumas vezes sem justificativa para isso.

Em outro ensaio, Bell e Morse (2001) apresentam o conceito de "prisão mental", o qual é introduzido a partir da constatação da predominância de indicadores explícitos de natureza quantitativa. A crítica dos autores não reside no emprego dessa perspectiva, mas sim na ausência (ou na ignorância) do emprego de outras, com destaque às perspectivas qualitativas implícitas. Sugere-se, como alternativa, a inclusão das pessoas da localidade nas quais os indicadores são construídos e aplicados, considerando que "o falem o que é importante para eles" consiste numa das formas de se sair desta prisão (BELL; MORSE, 2001).

$\mathrm{Na}$ contraposição das perspectivas sobre o mérito e o emprego de indicadores, observa-se a discussão entre (1) a defesa da flexibilidade metodológica para ampliar a perspectiva captada por indicador (agora não apenas quantitativo explícito), (2) e a defesa de aplicação de um maior rigor científico na construção de indicadores. Do ponto de vista acadêmico, um dos entraves encontra-se nas questões metodológicas inerentes à definição de um indicador. $\mathrm{Na}$ área de sustentabilidade, esse entrave acentua-se visto que o referencial teórico da área também não está consolidado. Bell e Morse (2001) destacam 
excesso de arbitrariedade e subjetividade em algumas escolhas, tais como ponderação e agregação de variáveis. Outra questão refere-se à dificuldade de utilização ampla dos indicadores, uma vez que o contexto regional/local difere significativamente, tornando os indicadores com aplicabilidade restrita a algumas regiões. Levando em conta essas particularidades locais, eleva-se a fidedignidade da avaliação, porém restringe-se sua aplicação.

$\mathrm{Na}$ avaliação dos indicadores qualitativos, então, a predominância está em compreender a percepção e a participação ativa dos sujeitos envolvidos na implementação do programa (MINAYO, 2005).

\subsection{EDUCAÇÃO AMBIENTAL NAS ORGANIZAÇÕES}

Estamos inseridos em um sistema econômico que estimula o consumismo, o individualismo e a competição e por isso criamos um meio de produção que favorece a degradação do meio ambiente. Layrargues (2003) afirma que empresas, ao assumirem uma postura rumo à sustentabilidade, não o fazem exclusivamente por desprendimento, generosidade e responsabilidade social, mas porque os moldes do sistema econômico capitalista exigem essa transformação. A crise de esgotamento de recursos naturais e a crescente preocupação com a emissão poluente ameaçam as condições de produção capitalista (VITORASSI, 2014). Logo, é emergente a necessidade de se revisar a forma como criamos necessidades na sociedade contemporânea e de reavaliar nossa forma de utilizar recursos.

Assim, verifica-se a transformação de pensamento, considerando a ética relacionada ao meio ambiente. Essa perspectiva foi apresentada pela primeira vez no relatório Brundlandt, de 1987. Buscou-se, então, estimular não só a interação entre as questões econômicas, tecnológicas, sociais e políticas, como também uma nova postura ética quanto à responsabilidade com as próximas gerações, bem como a interação interdisciplinar dos integrantes da sociedade e seus papéis (BRASIL, 2003).

A transformação da postura perante nossa responsabilidade com o ambiente e a sociedade influencia não só a atuação das empresas, mas a opinião pública e a intervenção do Estado, como, por exemplo, a aprovação da Lei 9.605, 12 de fevereiro de 1998, que trata de crimes ambientais (BRASIL, 1998). Caballero, Morales e Lopes (2004) levantam que a inserção da sustentabilidade nas ações organizacionais é justificada também pela 
globalização, por padrões de qualidade ambiental internacionalizados, pelo crescente consumo consciente, estes dois últimos difundidos pela educação ambiental.

Inclui-se também a transformação das organizações em repensarem suas ações deliberadas não mais limitadas a oferecer treinamentos aos seus empregados (DEMAJOROVIC, 2003), mas também em assumir o papel central de educador ambiental na promoção de uma nova relação com a comunidade do entorno organizacional, inserindo valores e estimulando habilidades em busca da sustentabilidade, a fim de tornar o papel da educação ambiental como o de "[...] promover o diálogo e o enfrentamento individual e coletivo em relação às questões do desenvolvimento" (VITORASSI, 2014, p. 56).

No Brasil, foi estipulada a Política Nacional de Educação Ambiental pela Lei $\mathrm{n}^{\circ}$ 9.795, de 27 de abril de 1999, cujo artigo $1^{\circ}$ define:

[...] os processos por meio dos quais o indivíduo e a coletividade constroem valores sociais, conhecimentos, habilidades, atitudes e competências voltadas para a conservação do meio ambiente, bem de uso comum do povo, essencial à sadia qualidade de vida e sua sustentabilidade (BRASIL, 1999).

Por definição, essa política de disseminar a educação ambiental incumbe ao Poder Público, às Instituições Educativas, aos órgãos integrantes do Sistema Nacional de Meio Ambiente (SISNMA), às empresas (públicas ou privadas) e à sociedade como um todo. Denota-se também a característica da educação ambiental como forma praticada tanto no meio formal (público escolar de todos os níveis) como no informal (qualquer ator social com capacidade de intervir no meio em que vive).

Embora reconhecido o caráter transformador da educação ambiental, na qual o desenvolvimento sustentável dependerá de os indivíduos assumirem a corresponsabilização pela utilização e manutenção dos recursos, Tamaio (2000) atenta para ela como mais uma ferramenta a ser utilizada na interação entre culturas, entendendo que estas têm comportamentos de consumo diferentes e interesses específicos de grupos sociais, em prol das transformações almejadas. A educação ambiental servirá, então, como mediadora na criação de referências ambientais, quando na prática social voltada à natureza.

Jacobi (2003), em sua reflexão sobre práticas sociais para a necessidade de articular a educação ambiental num contexto de degradação do meio ambiente, comenta que a educação representa uma possibilidade de angariar pessoas na participação de processos, a fim de minimizar os efeitos degradantes da sociedade, bem como de aumentar o controle social da coisa pública. Ou seja, a educação é capaz de criar condições favoráveis de 
ruptura de práticas degradantes, para uma proposta de nova sociedade baseada em participação por meio da educação.

O processo de educação ambiental pode ser implementado nas empresas por um Sistema de Gestão Ambiental (SGA), com a realização de cursos ou palestras, em setor próprio ou por meio de contratação de consultorias especializadas, tanto para funcionários quanto para a sociedade em que está inserida. Nesse contexto, a ISO 14.001 (ABNT, 2017) certifica empresas comprometidas com a redução contínua de poluição gerada e melhorias, inseridas no processo de produção normal baseada no ciclo PDCA - plan-do-check-at - ou seja, assumir o compromisso com as políticas ambientais atuais, bem como comunicar e transmitir suas ações a terceiros.

Contudo, a cultura de avaliação dos programas desenvolvidos rumo à sustentabilidade por diferentes atores sociais (Estado, organizações públicas ou privadas, ONGs, sociedades organizadas, ou a comunidade geral) ainda é recente e escassa no Brasil. Pode-se destacar a importância de um sistema de avaliação desses programas como forma de justificar investimentos internos ou externos, seja de capital ou de pessoal. Vitorassi (2014) reforça a importância de um sistema de avaliação, ressaltando que a informação decorrente da avaliação é capaz de subsidiar decisões gerenciais, por meio de um processo estruturado de coleta e análise de informações, características, respondendo a questões avaliativas, bem como a relação entre ele e seus efeitos.

\section{Procedimentos metodológicos}

O estudo caracteriza-se pela utilização do método de estudo caso único (YIN, 2001). A investigação de natureza qualitativa configura-se como pesquisa exploratória, tendo em vista o número relativamente baixo de trabalhos que abordam questões relacionadas à educação ambiental com indicadores de sustentabilidade. O propósito dessa pesquisa foi analisar um projeto desenvolvido pela Usina Hidrelétrica de Itaipu para promoção de encontros/oficinas de educação ambiental com os pescadores profissionais que atuam ao longo do reservatório (região da cidade de Foz do Iguaçu até a cidade de Guaíra), a partir de uma perspectiva de análise que conciliasse indicadores de resultado de natureza quantitativa e qualitativa. Trata-se de 456 pescadores profissionais cadastrados, lotados em 10 colônias/associações de pesca, distribuídos ao longo do Reservatório de Itaipu. 
Um exame bibliográfico e documental foi realizado para identificar possíveis frentes de pesquisa no tocante ao tema, considerando que a literatura tem sugerido a conciliação de indicadores quantitativos e qualitativos, em face das questões relacionadas à mensuração dos resultados, proximidade com as idiossincrasias de um projeto voltado à educação ambiental, rigor metodológico, entre outras questões. Foram avaliados e selecionados previamente tais elementos, definidos com base na revisão da literatura especializada e na pesquisa documental na área de gestão ambiental e educação ambiental da usina hidrelétrica que serviu de foco para esse estudo. Outros eventuais fatores foram embutidos em questões que buscavam explorar as idiossincrasias das interações e do contexto no qual se encontram inseridas (GODOY, 2006).

A partir da definição do objetivo de pesquisa, foi percorrido o seguinte percurso: (1) exame dos termos contratuais e planos de trabalho do projeto de educação ambiental, assim como as justificativas, histórico de comunicação de Itaipu com as colônias e associações de pescadores; (2) entrevistas com os atores que participam ativamente desse projeto; (3) observação não participante de duas oficinas de educação ambiental nas colônias de São Miguel do Iguaçu e Santa Terezinha de Itaipu; (4) visita a oito pontos de pesca nos quais foram realizadas melhorias a partir do projeto investigado; (5) análise dos relatórios das oficinas de educação ambiental redigidos pela empresa parceira de Itaipu que atua como intermediadora do projeto; (6) novo contato com os entrevistados para esclarecer eventuais dúvidas. A coleta de dados ocorreu entre março e julho de 2016.

As entrevistas foram realizadas da seguinte forma: cinco entrevistas com gestores envolvidos no projeto, três entrevistas com pedagogas pertencentes à empresa intermediadora do projeto, duas entrevistas com presidentes de duas colônias de pescadores.

Com relação à perspectiva temporal, a pesquisa enquadra-se como transversal, com aproximação de corte longitudinal, pois foram abordados, durante as entrevistas, temas e fatos passados, necessários à compreensão do contexto do projeto de educação ambiental e ao entendimento da trajetória da classe de pescadores profissionais daquela região. O nível de análise da pesquisa foi organizacional e a unidade de análise é representada pelo projeto de educação ambiental pesquisado. Para a análise e interpretação dos dados, utilizou-se a análise de conteúdo.

\section{Descrição do projeto e resultados}

Rev. Eletrônica Mestr. Educ. Ambient. Rio Grande, v. 36, n. 2, p. 126 -147, mai./ago. 2019. E-ISSN 1517-1256 
O quadro a seguir sintetiza o propósito e a sequência formal das iniciativas adotadas nesse projeto de educação ambiental.

Quadro I - Descrição dos objetivos e atividades

\begin{tabular}{|c|c|c|}
\hline $\begin{array}{l}\text { Propósito } \\
\text { geral }\end{array}$ & \multicolumn{2}{|c|}{$\begin{array}{l}\text { - Estimular a formação de uma cultura sustentável e cooperativa nas comunidades de } \\
\text { pescadores, que contribua para a melhoria da qualidade de vida, a partir da valorização da } \\
\text { atividade pesqueira e da profissão de pescador. }\end{array}$} \\
\hline $\begin{array}{l}\text { Propósitos } \\
\text { específicos }\end{array}$ & \multicolumn{2}{|c|}{$\begin{array}{l}\text { - Estimular nos participantes a reflexão para os problemas de sua realidade, por meio do } \\
\text { debate sobre os conflitos sociais e ambientais que atingem a atividade de pesca na região. } \\
\text { - Destacar a importância das colônias de pescadores enquanto organizações comunitárias } \\
\text { representativas da categoria e debater alternativas para o desenvolvimento institucional } \\
\text { delas. } \\
\text { - Explorar as ideias fundamentais da economia solidária para estimular a adoção de uma } \\
\text { rede de relacionamentos mais saudáveis, respeitosos e amigáveis para consigo, com os } \\
\text { outros e com o meio ambiente. } \\
\text { - Acompanhar o desenvolvimento do plano de ação construído pelos participantes. } \\
\text { - Estimular a autoavaliação dos participantes em relação ao seu comprometimento com as } \\
\text { ações e com o exercício da liderança e cidadania. }\end{array}$} \\
\hline & 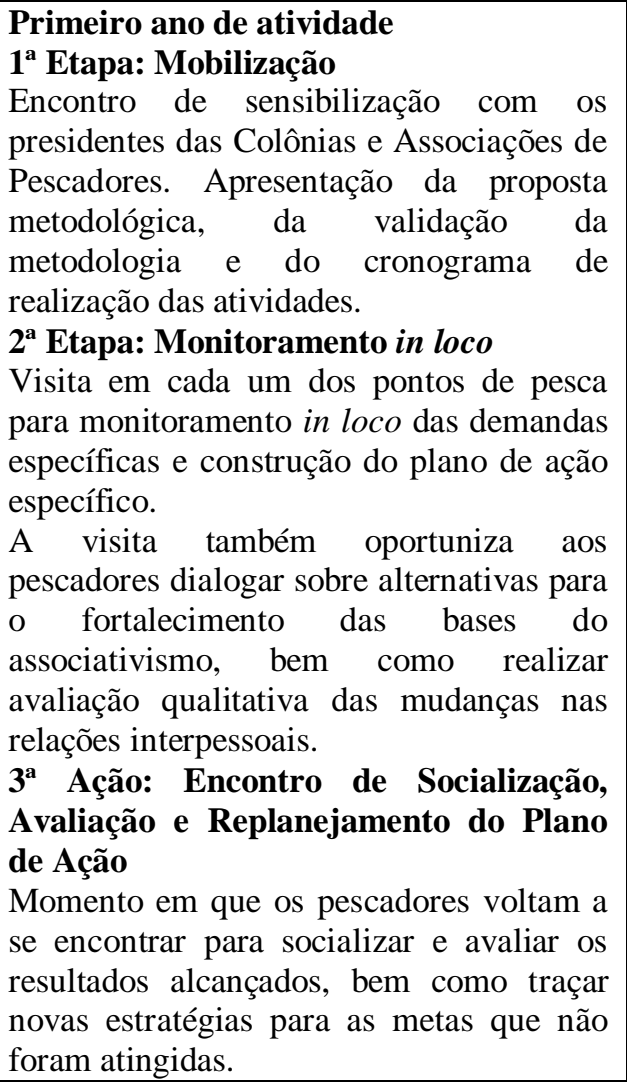 & 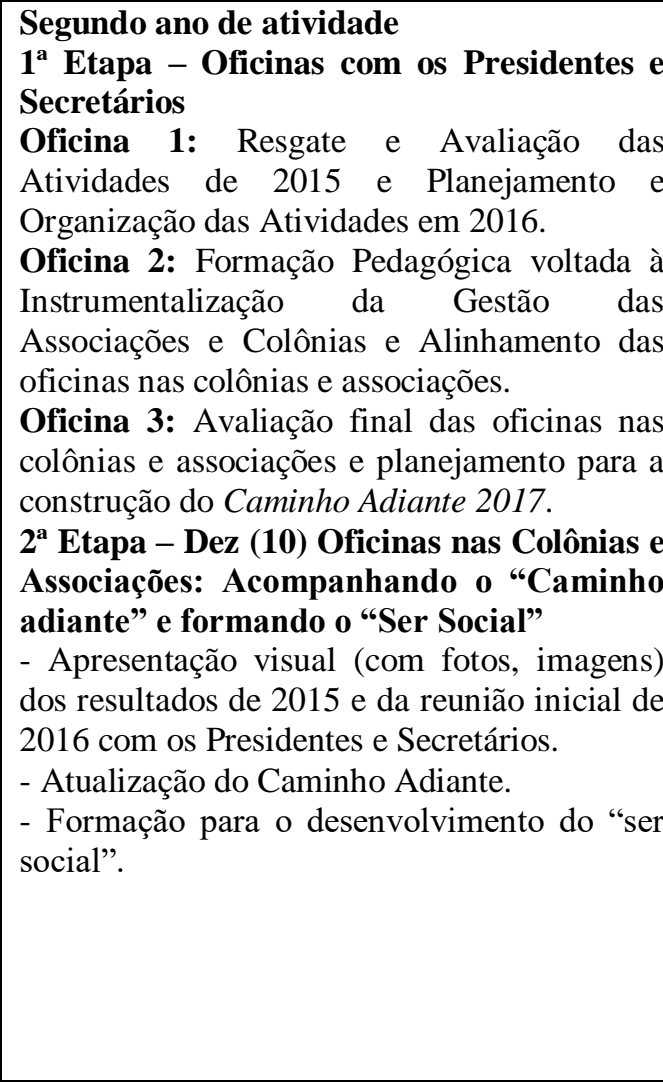 \\
\hline
\end{tabular}

Fonte: Os autores, com base na coleta de dados (2018).

Segundo relato dos entrevistados envolvidos no desenvolvimento dessas oficinas, as concepções de educação ambiental e de relações humanas têm norteado todas as atividades formativas, instigando os participantes a refletirem diante dos problemas socioambientais que afetam a qualidade de vida, a fim de assumir uma postura participativa enquanto cidadãos. Durante a participação dos pesquisadores nas oficinas 
formativas, nas sedes de algumas colônias de pescadores, observou-se a carência de informação desses grupos em relação a não conhecerem seus direitos (enquanto profissionais da pesca) e deveres, como também os órgãos públicos com os quais devem relacionar-se para tratar de determinado tema. Foi constatado ainda o quanto essas lacunas de informação acabam tornando a postura da classe dependente de outras instituições. Segundo relato de um dos profissionais organizadores dessas oficinas:

Quando nos aproximamos, a ideia era tratar exclusivamente da relação deles (pescadores) com o meio ambiente. Contudo, percebemos que se não discutíssemos temas ligados à cidadania, valores do grupo, comprometimento etc., todo o projeto iria por água abaixo [...] eles não conhecem o mínimo, não sabem o que é a responsabilidade de cada um [...] (Entrevistado 1).

Outro ponto abordado, exclusivamente com os presidentes das colônias e associações de pescadores, refere-se à formação pedagógica voltada à liderança: defendeuse a necessidade de os representantes tomarem determinadas iniciativas para defender os interesses daquele grupo. Foram questionados que tipo de iniciativas foram incitadas e por quais razões. A respeito dessa última, um dos entrevistados relatou:

Os presidentes das colônias e associações tratavam só de receber as mensalidades, cadastrar novos associados e manter a sede. Não havia disposição para marcar uma reunião com o prefeito pedindo, por exemplo, extensão da rede elétrica até algum ponto de pesca ou com o IAP, ou ainda com a polícia para relatar algum crime. De vez em quando mandam um ofício para a empresa (Itaipu) solicitando algo [...] o problema era que para defender os interesses, o presidente precisava reunir o grupo e discutir, o que dificilmente acontecia (Entrevistado 4).

Foi constatado, nessa etapa da coleta de dados, que havia, além dos objetivos supradescritos para esse projeto, dois tipos de interesse por parte dos técnicos da Itaipu, um de natureza técnica, outro institucional: (a) fazer com que os pescadores compreendessem o papel da Itaipu como geradora de energia elétrica, o que condiciona a operação do reservatório e as influências sobre a pesca; esclarecer as questões técnicas de operação do lago - sua variação de nível; (b) promover o fortalecimento das relações com a empresa enquanto instituição parceira das colônias e associações, a fim de demonstrar os benefícios do associativismo.

\section{Principais resultados}

Dentre os principais resultados desse projeto, destacam-se:

Rev. Eletrônica Mestr. Educ. Ambient. Rio Grande, v. 36, n. 2, p. 126 -147, mai./ago. 2019. 
a) Na primeira etapa: realização de uma oficina de mobilização com os presidentes das colônias e associações; 55 oficinas nos pontos de pesca; 10 encontros de avaliação, um em cada colônia e associação de pesca. Na segunda etapa: 3 oficinas com os presidentes das colônias e associações de pesca para avaliação e acompanhamento dos resultados e formação em gestão; 10 oficinas de educação ambiental envolvendo todos os pescadores das colônias e associações (em média, participação de $80 \%$ dos associados em cada evento).

b) Desenvolvimento de ações de controle de formigas e recuperação de matas ciliares nas proximidades dos pontos de pesca.

c) Instalação de lixeiras e um sistema de coleta de resíduos em parceria com as prefeituras e adoção de placas de sinalização nos pontos de pesca.

\subsection{Além dos resultados quantitativos/tangíveis}

Durante as entrevistas com os técnicos da Itaipu envolvidos com as atividades de educação ambiental e com as pedagogas da empresa que realizam a intermediação desse projeto, foram abordadas questões relativas à interpretação de cada um a respeito de quais indicadores estão perceptíveis, mas que não são avaliados/mensurados, em decorrência de sua natureza qualitativa. O quadro a seguir sintetiza as respostas obtidas.

Quadro II - Indicadores qualitativos

\begin{tabular}{|l|l|}
\hline \multicolumn{1}{|c|}{ Indicador } & \multicolumn{1}{c|}{ Constatações } \\
\hline $\begin{array}{l}\text { Melhora na capacidade de } \\
\text { reconhecer outros atores e } \\
\text { instituições }\end{array}$ & $\begin{array}{l}\text { - Anteriormente, a usina de Itaipu era percebida como responsável por } \\
\text { qualquer mazela que ocorresse para esta classe, a exemplo de problemas } \\
\text { ambientais, alteração no nível do reservatório, mortalidade de peixes. Os } \\
\text { pescadores não sabiam de quem era a responsabilidade, ou seja, as } \\
\text { atribuições de órgãos federais ambientais, órgãos de fiscalização, } \\
\text { prefeituras etc. Durante o desenvolvimento desse projeto, foi possível } \\
\text { observar aumento da proatividade da classe, maior envolvimento e } \\
\text { mobilização conjunta para defender/pleitear seus interesses. }\end{array}$ \\
\hline $\begin{array}{l}\text { Melhora da relação da } \\
\text { Itaipu com as colônias e } \\
\text { associações (gestão do } \\
\text { relacionamento } \\
\text { stakeholders) }\end{array}$ & $\begin{array}{l}\text { - Embora a Itaipu realize, desde 1986, atividades de monitoramento da } \\
\text { pesca profissional na sua área de influência, até então não tinha havido } \\
\text { projeto similar que propiciasse o estreitamento das relações entre a classe } \\
\text { de pescadores e a usina. }\end{array}$ \\
\hline $\begin{array}{l}\text { Aprimoramento questões de emancipação } \\
\text { da classe das }\end{array}$ & $\begin{array}{l}\text { - Nos contatos iniciais com a classe, foi constatado, na declaração de um } \\
\text { dos organizadores do projeto "a necessidade de 'começar do zero' antes } \\
\text { de pe pensar em educação ambiental”. Foi ressaltado que as questões } \\
\text { relacionadas à educação ambiental só poderiam ser tratadas na } \\
\text { sequência, após um esforço para tratar de questões básicas, tais como: } \\
\text { direitos e deveres da classe, trabalho conjunto, identificação de atores } \\
\text { relevantes, etc. Segundo declaração de uma das pedagogas envolvidas: } \\
\text { "alguns presidentes de colônias nunca haviam escrito um ofício, não } \\
\text { sabiam a quem recorrer em cada situação, tampouco quais eram os }\end{array}$ \\
\hline
\end{tabular}

Rev. Eletrônica Mestr. Educ. Ambient. Rio Grande, v. 36, n. 2, p. 126 -147, mai./ago. 2019. 


\begin{tabular}{|c|c|}
\hline & direitos dos pescadores". \\
\hline $\begin{array}{l}\text { Sentimento de valorização } \\
\text { da classe }\end{array}$ & $\begin{array}{l}\text { - Foi ressaltado que o ato de 'ouvir as expectativas' dos pescadores } \\
\text { implicou na abertura de um canal para que seus problemas fossem } \\
\text { discutidos (durante as oficinas). Esse ato, na percepção dos } \\
\text { entrevistados, resultou num sentimento de valorização que até então não } \\
\text { existia. Aqui, cabe ressaltar que se tratam de pessoas - em sua maioria - } \\
\text { com pouco grau de instrução ou analfabetas. }\end{array}$ \\
\hline $\begin{array}{l}\text { Aumento do } \\
\text { engajamento/envolvimento } \\
\text { da classe }\end{array}$ & $\begin{array}{l}\text { - Foi constatado não apenas o aumento do número de pescadores nas } \\
\text { oficinas de educação ambiental, mas sobretudo o aumento de } \\
\text { interessados em como resolver os problemas e em buscar soluções } \\
\text { conjuntas com os demais associados. }\end{array}$ \\
\hline
\end{tabular}

Fonte: Os autores, com base na coleta de dados (2018).

$\mathrm{Na}$ intepretação de um dos entrevistados, “[...] haveria muito mais para se mostrar sobre este programa se estes dados (qualitativos) também fossem considerados”. Essa percepção vai ao encontro do que preconizam Bell e Morse (2001) a respeito da inclusão de especificidades locais na construção de indicadores, ainda que essa iniciativa demande a adoção de maior flexibilidade metodológica. Nesse cenário, o contexto local (e histórico) passa a ser considerado, possibilitando a ampliação do conhecimento sobre os seus resultados (BELL; MORSE, 2011). Do contrário, muito da evolução percebida acabaria não sendo visível a partir de um corte exclusivamente transversal de pesquisa, ou seja, perder-se-iam questões de médio e longo prazo relevantes à avaliação do projeto e à compreensão da trajetória dessa classe.

Cabe ainda considerar a representatividade do que não foi mensurado, mas que também serve de parâmetro à elaboração de políticas públicas voltadas ao atendimento das comunidades locais, assim como o estreitamento das relações da classe de pescadores com órgãos municipais, estaduais e federais. Os indicadores citados pelos entrevistados, relacionados à "emancipação da classe", consistem em informações tão relevantes quanto à quantificação do número de oficinas, uma vez que podem servir de referência ao aprimoramento de futuros projetos de educação ambiental (agora mais específicos) e para fomentar outras iniciativas que impliquem na melhora das condições de vida desses indivíduos. Por fim, depreende-se que a utilização conjunta de indicadores de natureza quantitativa com outros de natureza qualitativa pode ser útil, inclusive, para facilitar a utilização concomitante desses dados, fato que ainda carece de amadurecimento (RIGBY; HOWLETT; WODHOUSE, 2000 e 2000a).

Face ao exposto, essas idiossincrasias identificadas nas comunidades, nesse caso, pescadores profissionais lotados ao longo das áreas banhadas pelo reservatório de Itaipu, se consideradas por governantes locais, também poderiam oportunizar o surgimento de projetos correlatos, com forte interface aos dados coletados, tais como: cursos básicos e 
profissionalizantes, pesquisas na área da biologia e da pesca, entre outros. Tais iniciativas iriam ao encontro da argumentação de Bell e Morse (2001, p. 305): “[...] o que sentimos que precisamos fazer é nos envolver com as pessoas locais para compartilhar entendimentos sobre o que é importante em suas vidas",5.

A partir da perspectiva do modelo tridimensional de Bell e Morse (2001), os potenciais indicadores do projeto de educação ambiental são analisados na figura a seguir:

Figura II - Análise tridimensional do programa de educação ambiental para pescadores profissionais

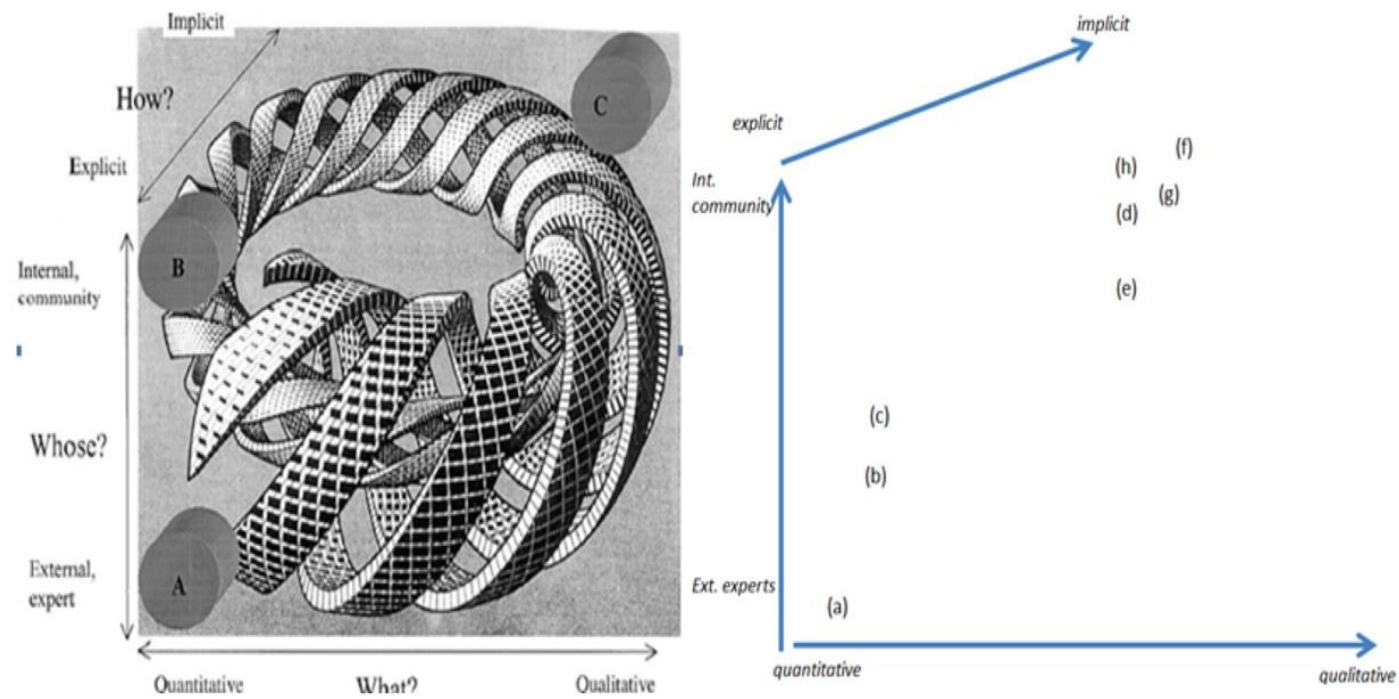

Fonte: Os autores, com base em Bell e Morse (2001).

Os indicadores listados com base no subprograma analisado são: (a) número de oficinas de educação ambiental; (b) ações de controle ambiental desenvolvidas; (c) instalação de lixeiras e programa de coleta de resíduos nos pontos de pesca; (d) capacidade de reconhecer outros atores; (e) melhora da relação da Itaipu com as colônias de pescadores; (f) amadurecimento das questões de emancipação da classe; (g) sentimento de valorização da classe; (h) aumento do engajamento/envolvimento da classe.

\section{Considerações finais}

O presente estudo procurou analisar um projeto desenvolvido pela Usina Hidrelétrica de Itaipu para promoção de encontros/oficinas de educação ambiental com os pescadores profissionais que atuam ao longo do reservatório, a partir de uma perspectiva

\footnotetext{
${ }^{5}$ No original: what we feel we need to do is to engage with local people to share understandings of what is important in their lives (BELL; MORSE, 2001, p. 305).
}

Rev. Eletrônica Mestr. Educ. Ambient. Rio Grande, v. 36, n. 2, p. 126 -147, mai./ago. 2019. 
de análise que conciliasse indicadores de resultado de natureza quantitativa e qualitativa. Sugere-se que o emprego concomitante desses indicadores demanda a ampliação da perspectiva temporal de análise (o projeto analisado foi iniciado em 2013 e ainda está em andamento), assim como maior aproximação do pesquisador com o fenômeno investigado, a fim de captar as especificidades e a história local, bem como as múltiplas interpretações dos envolvidos.

Um ponto de discussão concerne ao acompanhamento financeiro do projeto, que é realizado em paralelo aos indicadores quantitativos (mensuráveis), ao passo que os resultados mais relevantes - na percepção dos envolvidos - estão concentrados nos resultados qualitativos, os quais, pela sua natureza, não poderiam servir de referência ao acompanhamento da execução financeira. Tal constatação é corroborada quando, após a análise dos documentos e ao término das entrevistas com os membros organizadores do projeto, todos foram questionados sobre os desafios ainda identificados. As respostas, transcritas abaixo, foram:

- Ampliar a visibilidade da classe de pescadores.

- Fortalecer a disponibilização de políticas públicas para a classe.

- Minimizar a fragilidade dos atores sociais no que tange à visão de liderança e cidadania.

Essas declarações denotam ainda a necessidade de serem estabelecidas políticas públicas voltadas à emancipação da classe, a fim de possibilitar aos pescadores melhores condições de se trabalhar por uma vida melhor. A análise concomitante dessas questões, conciliadas à renda média da classe (1,3 salário-mínimo) e ao seu grau de instrução $(75,9 \%$ com Ensino Fundamental Incompleto ou analfabeto) sugerem a urgência da atuação pública.

O acompanhamento dessas iniciativas, assim como a avaliação longitudinal desse projeto e a forma como os indicadores qualitativos estão sendo considerados, representa uma sugestão de pesquisa futura. Outra indicação consiste na possibilidade de comparar esse projeto com aqueles desenvolvidos nas demais localidades do país. Essa iniciativa auxiliaria a observar as melhores práticas, assim como verificar as influências do contexto sociocultural local sobre os resultados atingidos.

\section{Referências}


ABNT. Associação Brasileira de Normas Técnicas. ISO 14.001 - Sistema de gestão ambiental. Disponível em: <https://certificacaoiso.com.br/iso-14001/>. Acesso em: 30 jul. 2017.

BARBIERI, J. C. Gestão ambiental empresarial: conceitos, modelos e instrumentos. 2. ed. São Paulo: Saraiva, 2008.

BARBIERI, J. C.; VASCONCELOS, I. F. G. de; ANDREASSI, T.; VASCONCELOS, F. C. de. Inovação e sustentabilidade: novos modelos e proposições. Revista de

Administração de Empresas, v. 50, n. 2, 146, 2010. Disponível em: <http://www.scielo.br/pdf/rae/v50n2/02.pdf>. Acesso em: 26 jul. 2017.

BELL, S.; MORSE, S. Breaking through the glass ceiling: who really cares about sustainability indicators? Local Environment, v. 6, p. 291-309, 2001. Disponível em: <https://doi.org/10.1080/13549830120073284>. Acesso em: 30 jul. 2017.

BELL, S.; MORSE, S. Sustainable Development Indicators: The Tyranny of Methodology Revisited. The Journal of Sustainable Development, v. 6, n. 1, p. 222-239, 2011. Disponível em: <https://www.jstor.org/stable/26167824?seq=1\#metadata_info_tab_contents>. Acesso em: 31 jul. 2017.

BOFF, L. Saber cuidar: ética do humano - compaixão pela Terra. 8 ed. Rio de Janeiro: Vozes, 2002.

BOHRINGER, C.; JOCHEM, P. E. P. Measuring the immeasurable: A survey of sustainability indices. Ecological Economics, v. 63, n.1, p. 1-8, 2007. Disponível em: <https://doi.org/10.1016/j.ecolecon.2007.03.008>. Acesso em: 31 jul. 2017.

BOULANGER, P.M. Sustainable development indicators: a scientific challenge, a democratic issue, S.A.P.I.E.N.S, v.1, n.1, p. 2008. Disponível em: <http://journals.openedition.org/sapiens/166>. Acesso em: 14 nov. 2018.

BRASIL. Lei $\mathrm{n}^{\circ}$ 9.605, de 12 de fevereiro de 1998. Dispõe sobre as sanções penais e administrativas derivadas de condutas e atividades lesivas ao meio ambiente, e dá outras providências. Diário Oficial da União, 13 fev., 1998, retificado em 17 fev. 1998. Brasília/DF. Disponível em: <http://www.planalto.gov.br/ccivil_03/LEIS/L9605.htm>. Acesso em: 27 jul. 2017.

BRASIL. Lei n ${ }^{\circ} 9.795$ de 27 de abril de 1999. Dispõe sobre a educação ambiental, institui a Política Nacional de Educação Ambiental e dá outras providências. Diário Oficial da União, 28 de abril de 1999. Brasília/DF. Disponível em: <http://www.planalto.gov.br/ccivil_03/leis/L9795.htm>. Acesso em: 31 jul. 2017.

BRASIL. Ministério de Minas e Energia. Empresa de Pesquisa Energética. Plano Decenal de Expansão de Energia 2023. Brasília: MME/EPE, 2014.

BRASIL. Senado Federal. Relatório Brundland, Nosso Futuro Comum. 2003. Disponível em: <http://www.senado.gov.br/noticias/Jornal/emdiscussao/rio20/temas-em-discussao-nario20/ecodesenvolvimento-conceito-desenvolvimento-sustentavel-relatorio-brundtland- 
onu-crescimento-economico-pobreza-consumo-energia-recursos-ambientaispoluicao.aspx>. Acesso em: 27 jul. 2017.

CABALLERO, O.; MORALES, J. B.; LOPEZ, C. B. Gestion ambiental en las empresas. Paraguai: Papyru's Impresiones, 2004.

CARSON, R. Silent spring. Boston, USA: Houghton Mifflin Harcourt, 1962.

CAVALCANTE, L.; BRUNI, A.; COSTA, F. Sustentabilidade empresarial e desempenho corporativo: uma analise do mercado brasileiro de ações. Anais... XXXII Encontro Nacional da Associação Nacional dos Programas de Pós-graduação em Administração ANPAD, Rio de Janeiro, RJ, 2007.

DEMAJOROVIC, J. Sociedade de risco e responsabilidade socioambiental: perspectivas para a educação corporativa. São Paulo: Editora Senac, 2003.

DYLLICK, T.; HOCKERTS, K. Beyond the business case for corporate sustainability. Business strategy and the environment, v. 11, n. 2, p. 130-141, 2002.Disponível em < https://doi.org/10.1002/bse.323>, Acesso em 27 jul. 2017.

ELKINGTON, J. Canibais com garfo e faca. São Paulo: Makron Books, 2001.

GODOY, A. S. Estudo de caso qualitativo. In: GODOI, C. K.; BANDEIRA-DE-MELLO, R.; BARBOSA DA SILVA, A. (Org.). Pesquisa qualitativa em estudos organizacionais. São Paulo: Saraiva, 2006.

INTERNATIONAL COUNCIL FOR LOCAL ENVIROMENTAL Initiatives - ICLEI. How local authoritie spend their bugest responsably: green puchrasing god pratice guide, 2000. Disponível em: <http://www. iclei.org>. Acesso em: 13 jul. 2016.

ITAIPU Binacional. Ecopedagogia: educação ambiental para sustentabilidade. Foz do Iguaçu: Edição Itaipu Binacional, 2010.

JACOBI, P. Educação ambiental, cidadania e sustentabilidade. Cadernos de pesquisa, v. 118, n. 3, 189-205, 2003.

KEATING, M. The Earth Summit's Agenda for Change, Centre for our Common Future, Geneva, 1993. Disponível em: <http://bahaifaith.manvell.org.uk/fragrant/agenda21/agenda21-1.html>. Acesso em: 12 abr. 2016.

LAYRARGUES, P. P. O desafio empresarial para sustentabilidade e as oportunidades da Educação Ambiental. In: LOUREIRO, C. F. B. Cidadania e meio ambiente. Salvador: CRA, 2003. p. 95-110.

MACHADO, M.; MACHADO, M.; CORRAR, L. Desempenho do índice de sustentabilidade empresarial (ISE) da Bolsa de Valores de São Paulo. Rev. Universo Contábil, v. 5, n. 2, 24-38, 2009. Disponível em: < http://proxy.furb.br/ojs/index.php/universocontabil/article/view/1401/01>. Acesso em: 12 abr. 2016. 
MIKHAILOVA. I. Sustentabilidade: evolução dos conceitos teóricos e os problemas da mensuração prática. Revista Economia e Desenvolvimento, n. 16, 2004, p. 1-20.

MINAYO, M. C. de S. Conceito de avaliação por triangulação de métodos. In: MINAYO, M. C. de S.; GONÇALVES, S. A.; SOUZA, E. R. Souza. Avaliação por triangulação de métodos: abordagem de programas sociais. Rio de Janeiro: Fio Cruz, 2005. p. 19-51.

MOLDAN, B.; JANOUSKOWÁ, S.; HAK, T. How to understand and measure environmental sustainability: indicators and targets. Ecological Indicators, v. 17, p. 4-13, 2012. Disponível em: <https://doi.org/10.1016/j.ecolind.2011.04.033 >. Acesso em: 12 abr. 2016.

ORSATO R. et al. Sustainability indexes: Why join in? A study of the corporate sustainability Index in Brazil. Journal of Cleaner Production., v. 96, p. 161-170, 2015. Disponível em: <https://doi.org/10.1016/j.jclepro.2014.10.071>. Acesso em: 20 ago.2017.

REZENDE, I. A.; NUNES, J. G.; PORTELA, S. S.; NASCIMENTO, A. P.; SALVADOR, N.; TELLES, T. E. Um estudo sobre o desempenho financeiro do Índice BOVESPA de Sustentabilidade Empresarial. Anais... XXXII Encontro Nacional da Associação Nacional dos Programas de Pós-graduação em Administração - ANPAD, Rio de Janeiro, RJ, 2007.

RIGBY, D.; HOWLETT, D.; WOODHOUSE, P. A framework for Research on sustainability indicators for agriculture and rural livelihood. Indicators for Natural Resources Management and Policy, Working paper n. 2, IDPM, University of Manchester, 2000.

RIGBY, D., HOWLETT, D.; WODHOUSE, P. A Review of Indicators of Agricultural and Rural Livelihood Sustainability. Manchester, Institute for Development Policy and Management, 2000a.

SILVIUS, A. J. G.; SCHIPPER, R. A. Maturity Model for Integrating Sustainability in Projects and Project Management. In: Proceedings of 24 IPMA World Congress, Istanbul, 2010.2 Disponível em: $<$ https://www.researchgate.net/publication/267228611_A_Maturity_Model_for_Integratin g_Sustainability_in_Projects_and_Project_Management>. Acesso em: 30 jul. 2017.

TAMAIO, I. A mediação do professor na construção do conceito de natureza. Dissertação (Mestrado) - Universidade Estadual de Campinas, Instituto de Geociências. Campinas, São Paulo, 2000.

UNESCO. The Rio Earth summit: summary of the United Nations Conference on Environment and Development. Nov. 1982. Disponível em: <http://www.publications.gc.ca/collections/Collection-R/LoPBdP/BP/bp317-e.htm>. Acesso em: 27 jul. 2017.

VITORASSI, S. Construção participativa de indicadores de avaliação do programa de Educação Ambiental de Itaipu Binacional. Tese (Doutorado) - Universitat de les Illes Balears. Departament de Pedagogia Aplicada i Psicologia de l'Educació, Palma de Mallorca, Espanha, 2014. 
WAGENHALS, S.; GARNER, W.; DUCKERS, L.; KUHN, K. Sustainability index with integrated indicator dependencies, Business, Management and Education, v. 12, n. 1, p. 15-29, 2014. DOI: 10.3846/bme.2014.02.

WCED. World Commission on Environment and Development, Report of the World Commission on Environment and Development: Our Common Future,1987. Disponível em: <http://www.un-documents.net/our-common-future.pdf>. Acesso em: 14 nov. 2017. YIN, R. K. Estudo de caso: planejamento e métodos. Porto Alegre, RS: Bookman Editor, 2001.

Submetido em: 25-04-2019.

Publicado em:20-07-2019. 